\title{
Article \\ Language Play with Formulas in an EFL Classroom
}

\section{Parvin Gheitasi}

School of Language, Literatures and Learning, Dalarna University, 79131 Falun, Sweden; pgh@du.se

\begin{abstract}
Language learners' play with language can be a useful and effective tool for learning. Since language play generally involves deviating from the norms, one potential source for it can be multiword units of language known as formulaic sequences. This study is informed by sociocultural perspective and Bakhtinian dialogism and investigates language play with sequences among young foreign language learners in a classroom context. A class of 11 pupils (aged 9 to 11), in Iran, was observed and video recorded for $16 \times 90$ min sessions. Across recordings, episodes where pupils were engaged in language play were identified and analyzed qualitatively to document patterns of use and participation. Additionally, formulaic sequences were identified based on pre-established criteria. Results revealed that the young learners of the present study were recurrently engaged in different types of language play with formulaic sequences such as playing with sounds, manipulating some units of sequences or using a sequence to play a role. The data provide examples illustrating the role of language play in generating occasions for learners to practice, repeat, explore, and interact with the language in a more lively and low stress environment.
\end{abstract}

Keywords: language play; early foreign language learning; formulaic sequences; classroom interaction

check for updates

Citation: Gheitasi, Parvin. 2022. Language Play with Formulas in an EFL Classroom. Languages 7: 63. https://doi.org/10.3390/languages 7010063

Academic Editors: Pia Sundqvist, Erica Sandlund, Marie Källkvist and Henrik Gyllstad

Received: 27 October 2021

Accepted: 28 February 2022

Published: 4 March 2022

Publisher's Note: MDPI stays neutral with regard to jurisdictional claims in published maps and institutional affiliations.

Copyright: (C) 2022 by the author. Licensee MDPI, Basel, Switzerland. This article is an open access article distributed under the terms and conditions of the Creative Commons Attribution (CC BY) license (https:// creativecommons.org/licenses/by/ $4.0 /)$.

\section{Introduction}

Language users, regardless of age, appear to have a drive to manipulate (or play with) language for the purpose of fun and enjoyment. Through different methods of conversation analysis, discourse analysis, and sociolinguistics, scholars have sought to understand the concept of language play, the functions language play serve, and the effect of such practices for language learning.

Language play not only gives pleasure and emotional excitement, but also leads to noticing and provides optimal circumstances for learners to improve a number of linguistic skills from language structure and syntax to pragmatic abilities (Bell 2012; Cekaite 2018; Cook 2000; Reddington and Waring 2015). By providing opportunities for focus on form and access to different types of interaction, language play facilitates second language acquisition (Cook 2000). According to Tarone (2000) language play may foster learning a second language in three ways: by reducing anxiety and lowering learners' affective filters, rendering language more memorable; by providing opportunities for learners to "try on different voices and language varieties"; and by destabilizing the interlanguage (p. 45).

Since language play generally involves deviating from norms and conventions, one potential source for it can be multiword units of language known as formulaic sequences (Bell 2012; Bell and Skalicky 2018). Formulaic sequences generally have a stereotyped form, conventionalized meaning, and require an appropriate context, all of which are immediately recognizable to native speakers of a language (Pawley 2007; Wray 2014). Such conventionalized systems provide an infinite number of options for language users to combine and manipulate elements of language; linguistic structures can be manipulated at the phonemic, morphological, lexical, syntactic, or pragmatic level. As language is a patterned system in which social norms regulate expectations concerning interaction patterns, speakers can manipulate these patterns as they co-construct a conversation.

This study links three areas of great importance in second/foreign language learning and applied linguistics research: (a) early foreign language learning, (b) language play, and 
(c) formulaic sequences. To date, the topic of language play with formulaic sequences in early language learning has received scant attention in the research literature. This paper reports on a study that investigates the nature and role of language play with formulaic sequences among young foreign language learners in a classroom context.

\section{Background}

\subsection{Theoretical Framework}

Vygotsky (1978) and Bakhtin (1986) provide theoretical frameworks that have influenced the two realms of play and language development. According to Vygotsky (1978; as cited in Lantolf 1997), the social dialogues children engage in during play contribute to the development of language. These dialogues are important because they are internalized as self-regulatory inner speech. Lantolf (1997) refers to Vygotsky's theory and argues that the purpose of play is not fun; it rather can perform an essential role in the cognitive development of learners by allowing them to handle parts of model utterances that are slightly beyond their current level of competence. According to this model, play creates a zone of proximal development in which the child "always behaves beyond his average age, above his daily behavior" (Vygotsky 1978, p. 102; as cited in Lantolf 1997, pp. 4-5). On the other hand, Bakhtin's (1986) theory of the dialogic process considers parody as a type of double voicing, in which the voice of the other is used for humor. Inspired by Bakhtin's notion of parody, Broner and Tarone (2001) argue that certain types of semantic play can also produce pragmatic effects where language users can distance themselves from certain positions and ridicule the serious reality. In fact, semantic language play provides an opportunity for the language user to creatively explore, practice, and generate fantasies without real, practical consequences. Bakhtin (1986) believed that we learn language by appropriating the voices of others. Every utterance stands in multiple dialogic relationships with other utterances, and they gain their true meaning through the interaction between a speaker, a respondent, and a relation between the two. This theory suggests that when the language learner acquires the varieties of others, they associate those utterances with the personal characteristics of those other speakers. Consequently, the learner adopts and retains the characteristics of different roles and registers and can employ them as desired.

Considering these two views of language play (as language practice intended mainly to be fun and as language practice intended to be rehearsal), Broner and Tarone (2001) argue that due to the multifunctionality of discourse, some utterances may appear to function as both fun and rehearsal.

\subsection{Language Play}

Language play refers to instances when language users manipulate the forms and/or functions of language as a source of fun for themselves and/or for others (Crystal 1998). Affirming that language users employ play primarily for enjoyment, Cook (2000) maintained that language play may take a variety of forms: linguistic (play with sound and grammatical patterns; repetitions), semantic (play with ambiguities; reference to an alternate reality), and pragmatic (play that focuses on performance and may be done for enjoyment and/or value, for example, in achieving solidarity).

Research in the field of applied linguistics has revealed various roles of language play in facilitating language learning (e.g., Bell 2005, 2012; Cekaite 2018; Cho and Kim 2018; Cook 2000; Hann 2017; Laursen and Kolstrup 2018; Reddington and Waring 2015). Several studies suggested that play can provide opportunities for noticing and encoding form as language users pay increased attention to language structures such as morphemes, phonemes, and lexemes (Bell and Skalicky 2018; Bushnell 2009; Cekaite and Aronsson 2005; Forman 2011). When language users are playing with or laughing about a certain aspect of language, their attention is directed towards it. Based on the results of a study involving three advanced second language learners, Bell (2012) claimed that language play may result in deeper processing of lexical items, rendering them more memorable. In a study of young language learners, Cekaite and Aronsson (2005) found that language play provided opportunities for 
extended practice and entailed learners' attention to phonological, semantic, and syntactic levels, promoting awareness of correct and incorrect phonology and morphology. Moreover, Reddington and Waring's (2015) study of adult language learners revealed that language play provides a safe space to rehearse different aspects of language, and at the same time to destabilize the interlanguage, keeping it open to change. In the same vein, observing multilingual children's text construction activity, Laursen and Kolstrup (2018) concluded that the pupils' engagement with language play led to a cheerful interaction where pupils playfully involved themselves in manipulating and exploring the aesthetic and creative potentials of language, and hence generating a space in which they simultaneously explored the possibilities of language to not only act in the world as it is, but also to generate new realities and their own social identities.

Language play has been found as an effective tool for developing learners' sociolinguistic competence via the appropriation of other voices (Bushnell 2009). Cekaite (2018) examined young learners' engagement in spontaneous language play through an interactional sociolinguistic approach. The findings of her study revealed incongruence as a generic and primary mechanism for creating amusement and entertainment that involved novel combinations of prior resources. Cekaite observed that the inversion of expectations and norms generated entertaining improvisations which could contribute to building and sharing norms and values.

During language play, when language users spontaneously and playfully focus on form, the episodes are "affectively charged" and the "emotional excitement" inherent in play may also contribute to noticing and rendering language forms as more memorable (Broner and Tarone 2001, p. 375). Hence, language play may trigger a classroom culture that encourages learners to participate and thus to make use of opportunities to produce language and receive feedback (Bell and Skalicky 2018; Cho and Kim 2018; Pomerantz and Bell 2011; Waring 2013). Moreover, language play can generate a sense of community among a group of language learners. Hann (2017) found that language play built rapport among the adult L2 students and contributed to their sense of communal identity.

\subsection{Formulaic Sequences}

It is becoming increasingly apparent that there is some level of fixedness in language; that is, some phrases and expressions have become conventionalized as more or less unanalyzed composites of form and function. These prefabricated chunks known as formulaic sequences are defined as: "a sequence, continuous or discontinuous, of words or other meaning elements, which is, or appears to be, prefabricated: that is stored and retrieved whole from the memory at the time of use, rather than being subject to generation or analysis by the language grammar" (Wray 2002, p. 9).

Developing on the psycholinguistic perspective of this definition, Wray (2002) suggests viewing formulaicity as the way a certain sequence is treated by a particular individual (learner internal approach), rather than attributing formulaicity to sequences in the language (learner external approach). The rationale for this statement is that a sequence that might be formulaic for one language user (e.g., for the speaker), need not be formulaic for another (e.g., for the listener). Likewise, introducing the term processing unit, Myles and Cordier (2017) define a learner internal sequence as "a multiword semantic/functional unit that presents a processing advantage for a given speaker, either because it is stored whole in their lexicon or because it is highly automatised" (p. 12).

During language acquisition, learners acquire and maintain many unanalyzed sequences of language linked to pragmatic competence in order to use them in some predictable social contexts (e.g., 'nice to meet you' for greeting). As language users' proficiency develop, they can start to analysis these prefabricated sequences and break them down into smaller patterns and individual words. Later, both the original sequence and the individual units and patterns of syntax, which come from analysis, can be retained (Nattinger and DeCarrico 1992; Wood 2015; Wray 2014). In the field of first language acquisition, there is some evidence suggesting that sequences that are learnt and retained as unanalyzed units 
are later segmented into individual words, which can be combined with other words in a novel utterance (Cameron 2001; Peters 1983). McKay (2006) claims that while exposed to the language in use, young language learners have a strong tendency to rely on a formulaic system. Through this, they gain implicit knowledge of language rules; later, they become able to generate their own constructions and discourse. Likewise, the two studies by Myles et al. $(1998,1999)$ suggest a developmental process from formulaic-based language production to lexico-grammatical productivity in the foreign language context. Their findings revealed that over the course of a year, the participants of their studies (11- and 12-year-old learners of French) progressed from using holistically stored interrogative forms to more analytically stored forms and used components in different ways.

On the segmentation of a formulaic sequence, some scholars believe that language users generally implement a conservative approach to processing. That is, they are reluctant to go beyond the things they have heard in the input or that they have often used themselves (Tomasello 2003; Wray 2014; Wray and Grace 2007). In line with the conservative approach to language processing, Wray (2002) has proposed the "Needs Only Analysis hypothesis" (p. 130). This hypothesis suggests that a language user analyses a sequence only if communication circumstances necessitate it. In both first and second language acquisition, young language learners analyze formulaic sequences only when required and more specifically to the extent that they are needed or when the possible changes have been indicated in the course of input (Wray 2002, 2014). This processing principle enlightens why some sequences are processed and stored more analytically than others. Language play entails situations where norms are violated and one way to do that is for language users to analyze and manipulate a formulaic sequence.

As a type of creative language use, language play is often dependent on formulaic language. In a review of the literature on relationship between formulaic language and language play, Bell (2012) concluded that formulaic sequences are rich resources for language play, which provides "particularly young second language learners" with an opportunity for both practice and analysis (p. 194). Formulaic sequences commonly have a stereotyped form, conventionalized meaning, and require an appropriate context, all of which are immediately recognizable to native speakers of a language (Pawley and Syder 1983; Wood 2015; Wray 2014). Such conventionalized systems provide an infinite number of options for language users to combine and manipulate elements of language; linguistic structures can be manipulated at the phonemic, morphological, lexical, syntactic, or pragmatic level. As Crystal (1998) described it, "to play with language requires that, at some level of consciousness, a person has sensed what is normal and is prepared to deviate from it" (p. 181). Since language is a patterned system in which social norms regulate expectations concerning interaction patterns, speakers can manipulate these patterns as they co-construct a conversation. Language users may consciously manipulate patterns in conversation, while they are aware of what is expected in the language (Huth 2017). In addition, this can be a way for learners to build up knowledge of formulaic sequences and/or language structure through experimentation. Concerning the memory effect of language play for learning, research shows that sequences that are encountered in a playful context are remembered better than those that were encountered seriously (Bell and Skalicky 2018).

All in all, the review of previous studies confirms that language play may contribute to a number of linguistic skills, including lexical, grammatical, and syntactic abilities. Language learners may also develop sociolinguistic skills through language play, and significant affective benefits seem to accompany this phenomenon. These advantages suggest that language play has great potential for application in the classroom particularly with young language learners, as among distinctive characteristics of young language learners are their enthusiasm for imitation, discovering things, and play (Pinter 2017; Scott and Lisbeth 1992). On the other hand, conventionalized formulaic sequences are pervasive in language and facilitate efficient communication, and contribute to aspects of accuracy and fluency (Wood 2015; Wray 2014). 
Despite their influential role in the process of language learning and the interdependence of the two, investigations into language play and formulaic language have largely taken place without reference to each other (Bell 2012; Bell and Skalicky 2018). The review of previous studies on both language play and formulaic language makes clear that this relationship needs to be examined. Moreover, young foreign language learners constitute a very large yet under-researched population in the field of language teaching and learning (Collins and Muñoz 2016; Enever 2018; Pinter 2017). Given the significant benefits of language play in the process of early language learning and the integral role of formulaicity in language play and in early language learning, this study aims to investigate the role and nature of language play with formulaic sequences among young language learners in a foreign language classroom.

\section{Materials and Methods}

The setting for data collection was a private language institute in Tehran, Iran. This context provides a good example of a foreign language setting, since learners are exposed to English mainly in the classroom (Davari and Aghagolzadeh 2015). Since the public educational system in Iran does not introduce English language to the pupils before grade 6 (age 11), parents who wish their children to learn English earlier need to send their children to a private language institute as an extracurricular activity. This study was carried out in one private language institute where the pupils were grouped based on their proficiency level and not on age; the age range of the pupils was between 9 and 11 years. Both the teacher and the pupils were Farsi native speakers and English was their foreign language. The lessons were based around the course material "Family and Friends" (Oxford University Press) and according to the institute's policy, teachers and pupils were expected to communicate only in English during the whole lesson.

Prior to collection of data, following the local procedures of the context, permission was obtained from the head of the school, the teacher, and the parents. Moreover, the pupils were informed about the study and their consent was also obtained. After an oral description of the research process by the researcher, the pupils were asked to read a short, informed consent (in their first language) and to circle a smiley face if they consented or a sad face if they were not willing to participate. A disadvantage with using a sad face and a smiley face as the response alternatives might be that pupils can feel obliged to choose the happy face since a sad face might be considered negative. However, the researcher tried to emphasize (both in oral and in written explanations) that participation was voluntary and that they had the right to withdraw from the study at any time.

To accomplish the purpose of the study, a classroom with 11 pupils was observed and video recorded for 16 sessions ( 90 min each). For each session, the video camera was installed at the front of the classroom at a point from which the whole classroom was visible. The researcher sat on a student chair in the corner of the classroom, keeping running logs about what was taking place in the classroom. The observation log provided a basis for becoming familiar with the data and the basic interpretations. Moreover, after the session was finished, the researcher could engage with the teacher as a collaborator to interpret certain instances and the possible reason(s) for certain behavior and activities observed.

After the data were collected, the initial task was to transcribe the recorded data. Due to the extensive amount of data collected and the limited time available for the study, not all recordings were transcribed. First, all the recordings were reviewed several times and then 10 sessions, which included more oral interaction activities than other sessions, were chosen to be transcribed. The other lessons were mostly focused on literacy skills and writing tasks or written exam. However, the recordings from all 16 sessions were reviewed and all episodes where learners were engaged in language play were transcribed. A number of transcription codes were adopted and adapted from Jefferson (2004) to indicate certain features such as hesitation, pause, and emphasis (see Appendix A).

The unit of analysis for the present study was stretches of talk treated by participants as humorous, which included transformations of various linguistic features. To identify 
and analyze language play instances in the data, certain guidelines derived from the review of literature were implemented in this study. Language play incorporates a wide variety of actions, through manipulations of language at three levels of linguistic form, meaning, or use. For the purpose of this study, I applied Cook's (2000) description of the defining features for each of these levels, such as repetition and patterning (formal), separation from 'real-world' reference (semantic), and social inclusion and or exclusion (pragmatic). Cook suggests that it is not necessary that all features be present in each instance. Likewise, in this study, the presence of one or more of these features was acknowledged as an indication of language play. Furthermore, some of the embodied actions relevant to the production of language play were taken into consideration. These actions could be smiles, laughter, marked shifts in vocal pitch and quality, reference to fictional worlds, repetition (or use of linguistic forms already known to the learner), or recycling the format of the prior turn, while changing some of its elements (Bell 2005; Broner and Tarone 2001). These contextualization cues were used to facilitate the identification of language play in the present study.

Given that one of the topics that this study is interested in is formulaic language, it is essential to specify how formulaic sequences were identified. As mentioned earlier in Section 2.2, this study adopted a learner internal definition of formulaic sequences-that is, a sequence treated as a whole unit by an individual language user. Previous studies with a learner internal approach to the definition and identification of formulaicity suggest using a criteria checklist for the identification of formulaic sequences (e.g., Myles 2004; Wood 2015). One of the most comprehensive identification checklists was presented by Wray and Namba (2003), and it is applicable to many types of data and is quite refined (Wood 2015). This checklist was adopted for the purpose of this study. As suggested by Wray and Namba (2003), it is not necessary for each of the selected sequences to meet all of the criteria; some sequences can be distinguished as formulaic if they meet one or two criteria.

- Well-formedness of a sequence compared to a more creative language production (a sequence beyond the speaker's current knowledge of grammar)

- Odd syntactic or semantic function in the sentence

- Phonologically coherent utterance (fluently articulated, non-hesitant)

- A sequence used repeatedly in the same form

- A particular formulation, which is the one most commonly used by the individual speaker when conveying a specific idea (i.e., individualized sequences which learners use repeatedly)

- A sequence associated with a particular situation (e.g., during a game: "It's my turn")

- Community wide in use (shared classroom knowledge; sequences that learners use frequently in their class, e.g., "May I go out")

- The repetition of the previous utterance (e.g., "I think, I think, I think we need this")

- Combined with other language units without applying necessary change. (e.g., "I love you horse")

Following the identification of the language play episodes, a detailed, turn-by-turn analysis of the language play incidents was conducted to reveal ways in which pupils do language play in the classroom context. Following the identification of language play instances, the episodes were further investigated to analyze the nature of language play and the role of formulaic sequences in these occasions. Language play instances were categorized according to the three levels of form, meaning and use applying the defining features introduced by Cook (2000). This part of the analysis was applied to examine the different ways that pupils were engaged in language play, employing formulaic sequences for the purpose of humor across the varied sessions.

\section{Results}

Analysis of the pupils' interactions revealed that the young language learners of this study were engaged in different types of play with language. Language play was a recurrent and spontaneously occurring verbal activity, situated in and related to the 
pupils' ongoing social practices. There was at least one instance of language play taking place during each lesson that was observed and transcribed. It was observed that the play episodes could take between 5 and $15 \mathrm{~min}$ (in total) of a lesson. A sufficiently relaxed classroom atmosphere allowed for this kind of play to happen. The teacher was highly skilled in knowing when to allow the play to continue and when to move on to the next task. Below an analysis of the different instances of language play is presented, with elaborations of illustrative examples for each category. It should be remembered that for the purpose of confidentiality, pseudonyms were used.

\subsection{Sound Play}

The participants of this study seemed to enjoy the potential for a simple but enjoyable game with the sounds of English. Sometimes the input they received could trigger their attention; they started to laugh, imitate, and exaggerate the sounds, and hence they repeated the sequence several times. The following extracts, numbered (1) and (2), are some of the occasions when pupils were engaged in this type of language play.

(1)

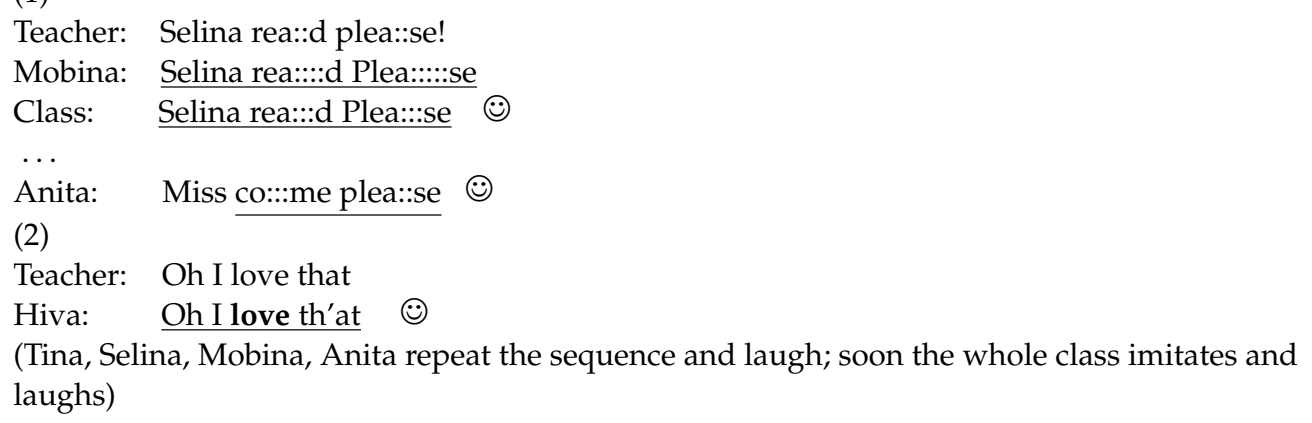

These types of play with sounds were common during the sessions. Instances of play with sound were found in 8 out of 10 lessons. Such instances appeared to engage all the pupils; even the more reserved and silent learners were also engaged and seemed to have fun. These occasions could provide opportunities for all the learners to practice repeating the input. As illustrated in examples (1) and (2), when the young learners were engaged in sound play, they repeated the sequences that they heard. During this procedure the pupils practiced language by repeating it and also hearing it from their peers, and in the meantime, they were having fun and laughing.

\subsection{Word Switching}

In addition to playing with the sounds through repetition and exaggeration, the pupils enjoyed partly analyzing formulaic sequences that they heard. On these occasions, first they initiated the play by repeating a sequence, then they substituted an element in a sequence with another element. Extract (3) presented below shows an occasion when the pupils had fun playing with the sound while also analyzing a sequence. In this example, the teacher asked the pupils to read their answers to the questions in the workbook. It was Sara's turn to read; however, she was talking to a friend and did not notice that it was her turn. The teacher tried to get Sara's attention and reminded her that it was her turn to read.

(3)

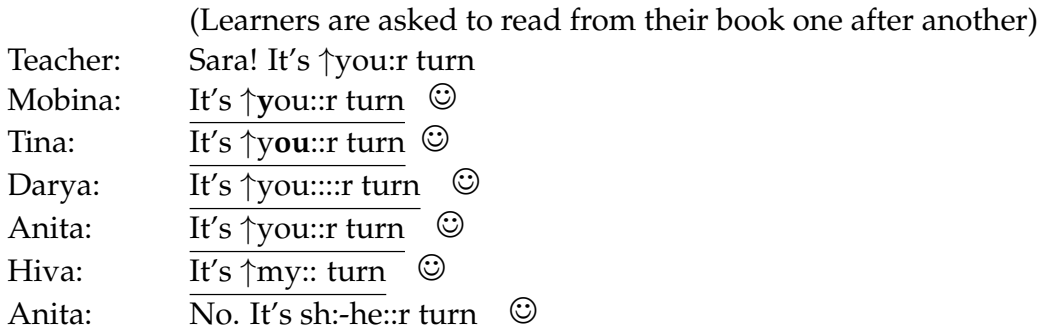

In example (3), the teacher tried to call Sara's attention to remind her that it was her turn to read. The teacher's statement drew Mobina's attention, who tried to reproduce the 
sequence playfully and exaggerated the sounds. Other pupils such as Tina, Darya, and Anita, who found it amusing, tried to follow Mobina and play with the pronunciation of the word your within the sequence it's your turn. Later, Hiva identified a potential substitution slot within the formulaic sequence and tried to refill it with another word. She replaced the pronoun your with my and produced the sequence it's my turn. Anita who wanted to correct her friend and point out that it was Sara's turn and not Hiva's, started to refill the slot with another element. She started to produce the pronoun she but then gathered that it was not suitable, and hence replaced it with a correct possessive pronoun (her) and produced the sequence it's her turn. This case demonstrates the pupils' play with a formulaic sequence through exaggerating the sounds and consequently repeating it several times. Moreover, this example distinctly illustrates pupils' engagement with language structure through manipulating a sequence, refilling a slot within the sequence and practicing the use of possessive pronouns with the sequence.

The following extract (4) presents another case where the pupils started to play with a sequence by refilling a slot within the sequence to refer to an alternate reality. On this occasion, the teacher asked the pupils a question about the weather outside, which was hot. The teacher had asked this question during previous lessons as well and the response had always been it's sunny and hot. Hence, both the question and the response could be considered as formulaic and prefabricated.

(4)

$\begin{array}{ll}\text { Teacher: } & \text { what's the weather like? } \\ \text { Class: } & \text { it's sunny and hot (gestures showing hot) } \\ \text { Hiva: } & \text { no (.) it's sunny and cold } \\ \text { Anita: } & \text { it's sunny and rainy }(-)\end{array}$

In response to the teacher's question, the pupils produced the fixed sequence it's sunny and hot. Since it was summer and the weather was hot, the sequence it's sunny and hot was found frequently in the data. Seeking fun through inversion of reality, Hiva analyzed the sequence and substituted the word hot with the opposite adjective cold. Anita who found this joke funny maintained this approach by substituting the same slot with another word (rainy). After the production of these sequences the whole class was laughing. This type of play with frequently used sequences happened quite often; there was at least one instance during each lesson where the pupils manipulated the repeatedly used sequences. The following extract (5) illustrates another case of this type, where pupils had fun modifying a part of sequences introduced in the book. The lesson was on negative imperatives and the teacher read some of the imperatives from the course book.

(5)

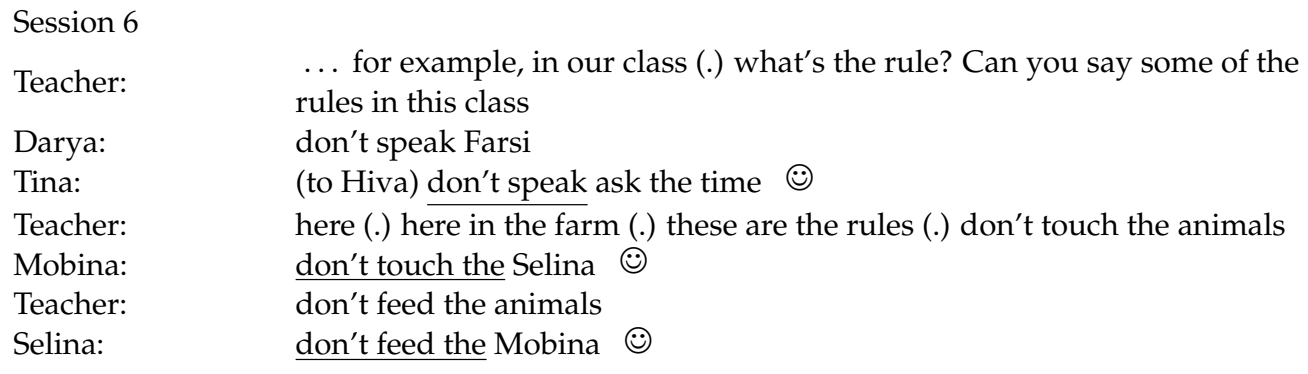

...

Session 8

Anita:

(Sara wants to touch Selina's hair and Selina does not let her) don't touch the Selina hair :)

Example (5) shows an occasion when some of the pupils tried to use a few sequences playfully. They had fun refilling a slot (at the end of the sequence) with words that were more familiar and humorous for them. They analyzed the sequences playfully. Two sessions later, one of the pupils (Anita) applied the sequence don't touch the Selina during a playful conversation with her friends. Although Anita heard this sequence only once during session 6, she could remember it after two lessons, and she applied it in the right 
context. This instance clearly demonstrates the potential facilitative influence of language play in pupils' language learning.

Below is another case, extract (6), where pupils had fun modifying a part of a sequences playing with two homophones (too/two).

(6)

$\begin{array}{ll}\text { Anita: } & \text { I (.) love (.) I love (.) Miss, I love birthda-birthd-birthday party } \\ \text { Teacher: } & \text { I love too } \\ \text { Dornaz: } & \text { me too } \\ \text { Darya: } & \text { me too } \\ \text { Selina: } & \text { me three } \\ \text { Tina: } & \text { me four }\end{array}$

Extract (6) presents an example of wordplay where language itself is manipulated. This type of wordplay is generally associated with semantics. The pupils created puns that exploited semantic ambiguity.

\subsection{Role Play}

Playing the role of a teacher is often a commonly occurring playful activity among pupils in classroom environments. This type of play seemed to be favored by the participants of this study. To inverse the social order and be the teacher, the pupils needed to imitate their language teacher as a role model. There were several occasions where pupils applied sequences that were frequently used by the teacher to play the teacher's role. On these instances they tried to produce the sequence with the same (or often an exaggerated) intonation pattern mimicking the pattern used by the teacher. For instance, in the following extract (7), the pupils were listening to a list of words and were supposed to repeat after a $\mathrm{CD}$ recording. The main purpose of this choral repetition was to practice pronunciation of new words.

(7)

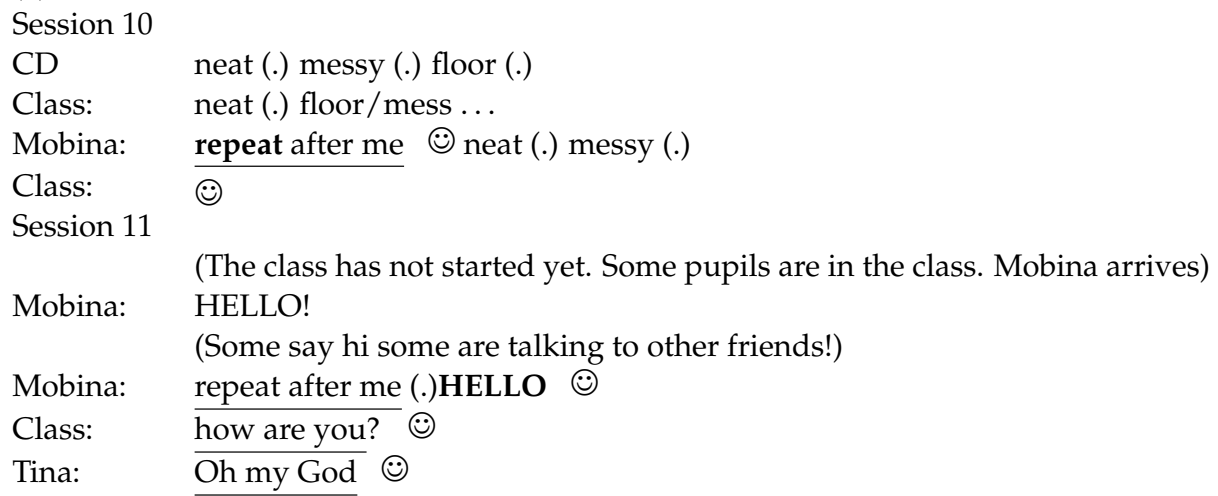

As the pupils forgot the order of the words, at one point, the choral repetition became chaotic. Usually, in these cases, the teacher would stop the CD and ask the class to repeat the word/sentence after her to remind them of the task. This time, when the teacher was going to stop the $\mathrm{CD}$, Mobina took the opportunity to play the role of the teacher, employing one of the teacher's frequently used sequences repeat after me. This led to laughter on the part of the teacher and the other pupils. The next session, before the class started, the pupils were in the classroom and were talking to their peers in Farsi (the teacher had not arrived yet). Mobina entered the class saying hello. There were not many replies from her classmates; hence, she stood in front of the class (where the teacher usually stands) and asked for a choral repetition of the word hello, using the sequence repeat after me. In response some of her peers used the sequence how are you, which was a joke with the greeting rituals that they had. Next, Tina used the teacher's other sequence oh my god. All of them were laughing and had fun using the teacher's frequently used formulaic sequences. Below is extract (8), from an instance when the pupils applied a sequence used by the teacher. 
(8)

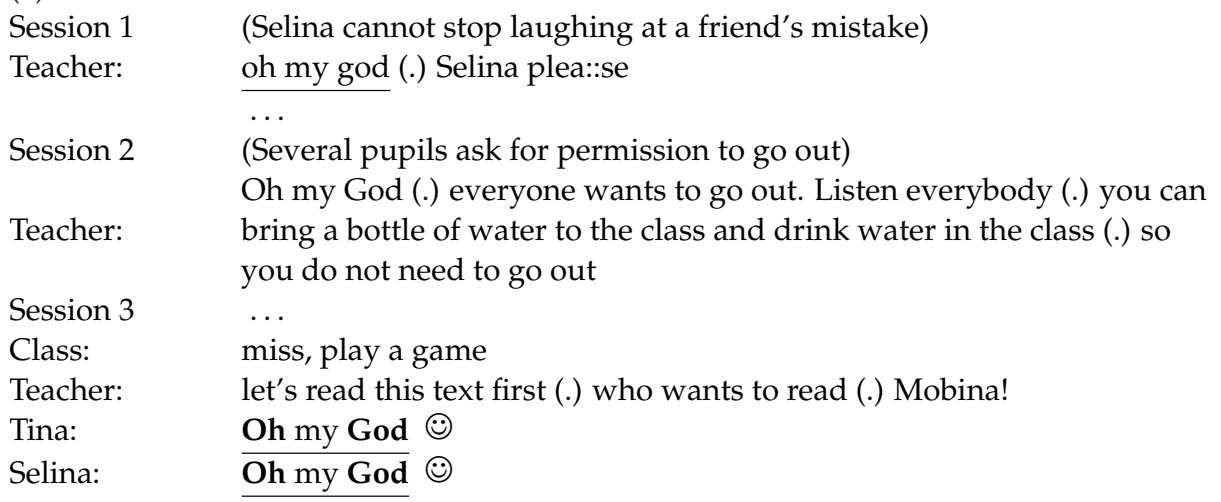

Analysis of the teacher's language disclosed that the frequent function of the formulaic sequence oh my god was an exclamation of frustration. The pupils adopted the sequence oh my god from the teacher's talk and applied it to their conversation with the same pattern. For instance, in the example above (8), the learners had heard the sequence oh my god on several occasions during session 1 and 2 . In session 3 , they wanted to play a game in the class but the teacher did not accept this request and instead asked one of the pupils to read the text. At this time, Selina and Tina employed the sequence oh my god, imitating the teacher, to show their frustration or disappointment. The sequence was produced with the same intonation contour that the teacher had previously produced but with a smile. It seemed that imitating the teacher's frequently used sequence allowed the pupils to express frustration or resistance, whilst at the same time mitigating this resistance in order to fit the classroom norms. In this example, play functioned as an interactional resource for renegotiating the task and experimenting with different voices.

Language play probably contributed to provide further opportunities to the acquisition of some of the teacher's sequences. In an attempt to play the role of a teacher, the pupils practiced their teacher's frequently used sequences and eventually added them to their respective linguistic repertoire. Since this type of play focused on mimicking and playing with the sounds more than the analysis of the sequences, it could appeal to all the pupils regardless of their language proficiency level and self-confidence. In these situations of imitations, even the less active pupils seemed inspired to repeat or imitate the sound pattern, and all the pupils seemed to be engaged and enjoy the play. Moreover, there were instances when the silent pupils also used the playful formulas, such as oh my god, in their speech.

\section{Discussion}

The results of this study indicated instances of all three types of language play presented by Cook (2000): linguistic, semantic, and pragmatic. The pupils enjoyed employing different types of language play, from playing with the sounds through exaggeration to violating sequential expectations as well as role expectations. The participants of this study were 11 young lively pupils with abundant passion for play. They might have been motivated to learn English or not, but they all appeared very fond of fun. This observation is in line with Pinter's (2017) description of young language learners' characteristics. She states that children are sensitive to sounds and the rhythm of language and they enjoy copying sounds and patterns of intonation. Moreover, children pick up and learn language if they have fun and if they can understand messages from meaningful contexts. These pupils could turn any potential situation into a game and were engaged in both 'play with' and 'play in' (see Bell 2012) English, where the former type dealt with instances in which the language itself was manipulated for play, and the latter with cases in which the language was used to engage in a play, such as playing the role of a teacher.

The data provided examples illustrating the role of formulaic sequences in the pupils' language play. Playing with formulaic sequences created opportunities for language learners to practice, repeat, explore, and interact with the language and at the same time to 
have fun. Although all the instances of language play observed in this study were initiated by the pupils during spontaneous classroom conversations, the teacher played a facilitative role in this process. Language play was individual, but mostly collectively evoked and sustained. Interestingly, language play appeared to promote a good mood among the pupils, who often laughed together as a result of having initiated such play. Research in the field of applied linguistics has revealed that, by lowering the affective barriers, language play enhances language acquisition (Bell and Skalicky 2018; Cho and Kim 2018; Cook 2000; Pomerantz and Bell 2011; Tarone 2000; Waring 2013). It should be noted that in the present study, the pupils who were engaged in language play could produce and recycle some of the language, but we do not know if this language had already been acquired.

The episodes of language play were accompanied with laughter and positive engagement of the pupils. This could indicate that, through language play, the pupils enjoyed language practice in a lively and low stress environment. These observations support claims by other researchers who assert that, besides fostering the development of linguistic and pragmatic abilities, language play may also result in significant affective benefits. It can increase language learners' motivation (Broner and Tarone 2001; Waring 2013), enhance community formation (Carter 2004; Cekaite 2018; Cekaite and Aronsson 2005; Hann 2017; Laursen and Kolstrup 2018), and contribute to communicative confidence and an affectively charged atmosphere (Bushnell 2009; Pomerantz and Bell 2011; Tarone 2000). In Section 3, a few examples were presented where learners of this study applied sequences that they played with such as oh my god or don't touch the Selina hair. This in turn seemed to lead to a facilitated acquisition of sequences. These findings are in line with the claims by other researchers who affirm that language play enhances internalization and acquisition of language by opening doors for learners to practice and develop deeper awareness of language (Bell 2005; Bell and Skalicky 2018; Bushnell 2009; Cook 2000; Laursen and Kolstrup 2018; Pomerantz and Bell 2011). When learners are playing with and laughing about a certain aspect of language, their attention is directed towards it and the positively charged atmosphere may lead to increased noticing.

Linguistic play with formulaic sequences appeared to help the pupils to practice the language, by both repeating a sequence and also by analyzing the structure. The results signified the facilitative role of language play on pupils' knowledge about language structure, by providing opportunities for them to focus on form. In order to manipulate a sequence and refill a slot within a sequence, the pupils were required to distinguish the type and function of the individual units and the structure of the sequence that they were playing with. For instance, in extract (3), when the pupils were playing with the sequence it's your turn, they needed to distinguish the nature of the unit, which was a possessive pronounm and then they could practice by substituting the pronoun 'your' with other pronouns, such as 'my' and 'her'. All in all, it appeared that refilling the slots within a sequence could boost pupils' awareness of different aspects of language structure. As Reddington and Waring (2015) argue, language play provides a safe space for rehearsal and can help to destabilize the interlanguage, keeping it open to change.

The young language learners of this study were engaged in Cook's (2000) linguistic, semantic, and pragmatic play to amuse themselves or others. For instance, in extract 6, presented earlier, pupils were engaged in semantic wordplay by using homophones (too, two). As Cekaite and Aronsson (2005) observed, such stretches of talk raise awareness of correct and incorrect phonology and morphology and may provide opportunities for extended practice. Again, we need to return to the notion of a safe space, as language play can offer not only protection from being held responsible for the content of a contribution, but also for the accuracy and appropriateness of the form in which it is conveyed (Bell and Skalicky 2018; Cekaite 2018; Laursen and Kolstrup 2018; Pomerantz and Bell 2011). In this way, language play provides learners with freedom to engage in a linguistic experiment while distancing themselves from threatening mistakes. As Broner and Tarone (2001) mention, language play can provide opportunities where the learners can distance themselves from 
certain positions and ridicule the serious reality to creatively explore, practice, and generate fantasies without real, practical consequences.

Although not all the pupils were initiators of language play, it appeared that when the play started it could engage all or the majority of the pupils in the classroom to a greater or lesser degree. The results revealed that there were only certain pupils (more experimental pupils) who always commenced play with language, and the more conservative pupils might get actively engaged with the play after some time or not at all. An interesting finding of the study was the observed impact of personality traits on pupils' engagements in language play. It was observed that some pupils did not engage in certain types of language play. One explanation could be that some pupils might be concerned about politeness, and therefore engaged in language play only if it did not clash with their personal view of classroom ethics. For instance, during the language play episode where some learners started to apply the sequence Oh my god (see extract 8) as an expression of frustration or resistance, two of the pupils sat silently and did not engage in the play at all. As Bakhtin (1986) states, the composition and style of speech can be highly affected by the speaker's attitude toward the others (listeners).

The observed tendency for play among the pupils can be explained by Hasselgren's (2000) and Pinter's (2017) description of young language learners' characteristics. They believe that young learners are open and enthusiastic to learning and have a particular need and capacity for play and fun. While this statement cannot be assumed to apply to all classroom contexts, in those situations where a skilled teacher is able to create a supportive atmosphere, opportunities for fun and play with language are more likely to be taken.

Bandura (1986) argues that children tend to follow the beliefs and behaviors of an adult who is perceived to be important. As an important adult, the teacher can be viewed as a role model by young language learners (see Nikolov 1999), and therefore plays an important role in the pupils' learning process, attitudes towards language learning, and their self-concept (Mihaljevic Djigunovic 2015; Nikolov 1999). Moreover, Bakhtin's (1986) concept of double voicing emphasizes that, in developing an utterance, language users tend to prefer words or sentences that they have heard from other speakers on similar occasions. Following Bakhtin's idea, Broner and Tarone (2001) claim that the appropriation of other voices is essential for a learner to become a fully competent language user, familiar with different registers and varieties of the language. Young language learners are often focused on their teacher and very likely to imitate the teacher and pick up their language since they idealize their teacher. It should be noted that the status of teachers might vary from one culture to another. Additionally, the concept of formulaicity focuses on the idea that language users pick up sequences that they have heard before and reuse them later to achieve increased fluency and accuracy. As observed in this study as well, the pupils seemed very keen to sound like the teacher or to play at being the teacher. One of the visible patterns of this type of play in this context was to employ the teachers' language in order to sound like her. The pupils picked up certain sequences from the teachers' language and tried to act out the role of the teacher in the classroom with their peers. This role playing resulted in incidental learning of a few formulaic sequences. A noteworthy feature of this play in the present study was that pupils mainly attended to sequences that the teacher applied in natural communications rather than sequences presented in the teaching materials. This evidence could relate to the significance of appropriation of an utterance for a language user, where learners acquire the utterances of others and associate those varieties with the personal characteristics of those speakers. By attending to the teacher's or peers' language, the pupils of this study could adopt and retain the characteristics of different roles and registers. This is in line with Cekaite's (2018) observations that the inversion of norms generated entertaining improvisations for the pupils.

By violating sequential expectations as well as role expectations, the pupils were effectively engaged in developing their sociolinguistic competence. The language practice of these pupils can be explained by Vygotsky's sociocultural perspective, which places the social context at the heart of learning and communication process. Vygotsky suggested that 
learning is highly affected by the social and cultural forces that influence the individuals (Toohey 2000). Like Vygotsky, Bakhtin (1986) claims that any instance of language use draws on conventions that embody specific social and ideological practices. Hence, to interpret the findings of this study, it is essential to consider the social context and setting of the classroom, the relations among the pupils and with their teacher, and the design and structure of the teaching and learning practices. In this context, learning English was an extracurricular activity that the parents of these pupils chose for them. The pupils needed to learn and use the language to be able to accomplish certain purposes. They aimed to please the teacher, to have fun, and to be able to assimilate into the group, following the rules of an English-only classroom. Bakhtin's (1986) view on the relation between the social context and the individual is evident in his notion of dialogism, which stresses that language emerges from the individual's communication with others. Bakhtin asserts that language users apply other speakers' utterances and through the process of appropriation they reflect on those utterances and shape them to their own intents (Toohey 2000). In the present study, among the most influential factors in the pupils' language practice were the roles of the teacher and the peers. Humor and play contributed to establishing a community. Through language play, formulaic sequences went through a process of appropriation. The pupils picked up sequences from their teacher or their peers and recycled them to communicate their intentions. This observation provides evidence for the significance of meaningful communication for the young language learners, confirming also the occurrence of incidental learning of formulaic sequences through language play. As Bakhtin (1986) argues, once the individual appropriates an utterance, it becomes the language user's personal understanding and accommodates to their mental schemata.

Finally, it is noteworthy to highlight, as several scholars have done, that humor and play often can be dependent on teachers' and learners' personalities; certain teachers and learners apply more examples of humor and play than others (Bushnell 2009; Laursen and Kolstrup 2018; Pomerantz and Bell 2011; Waring 2013).

\section{Conclusions}

Taken together, the findings of this study reveal that the young language learners evaluated herein took great pleasure in finding and creating fun in their studies. The pupils were engaged in linguistic, semantic, and pragmatic play, through which they could rehearse and explore language. These results suggest that encouraging language play in the young learner classroom and strategically harnessing its potential for specific learning purposes allows for genuine engagement and learning opportunities. Considering the findings of this study, it can be concluded that language play may accelerate language learning in the classroom in at least three ways: by fostering focus on form, by providing opportunities for pupils to develop sociolinguistic competence, and by promoting a classroom culture that supports and encourages participation.

Raising teachers' awareness regarding the role of language play and also formulaic sequences could valuably contribute to their effectiveness in implementing appropriate responses in the classroom situation. The data indicated that, although language play was a recurrent and possibly efficient strategy for pupils to both rehearse and explore the target language, and to provide a positive atmosphere in the classroom, there was no evidence of teacher-initiated language play. These findings suggest that teachers should be informed about the facilitative nature of language play in order to be able to orchestrate, foster, or simply support language play in the classroom. They can then employ formulaic sequences as sources for language play to aid pupils' language acquisition. It should be noted that this activity would demand very careful planning in larger classes. Equipped with this knowledge, teachers may be able to apply and encourage the facilitative functions of language play using formulaic sequences.

The role of language play with formulaic sequences in relation to learners' acquisition of language structures could be an interesting topic to be investigated in future research. A further avenue for investigations might be studies of specific pedagogical intervention 
where, for instance, different forms of language play with formulaic sequences are used in formal instruction for young language learners.

Funding: This research received no external funding.

Institutional Review Board Statement: Ethics approval for this project was granted by the institute board in Iran.

Informed Consent Statement: Informed consent was obtained from all subjects involved in the study.

Data Availability Statement: Data supporting the results are not publicly available at this time, due to the nature of the agreement with parents and the school to protect the privacy of the participating children. Enquiries about data can be made direct to the author.

Acknowledgments: I would like to extend my gratitude to the participants of this study.

Conflicts of Interest: The author declares no conflict of interest.

\section{Appendix A}

Transcription codes

The following codes have been used in the transcriptions in this text:

$X$

L1:

name of the speaker (anonymized)

[play]

indicates language production in first language (Farsi)

(0. 2): brackets are used for speech in first language

$s$ is shown by $(0.2)$ and so on.

Go::: $\quad$ one or more colons indicate extension of the preceding sound or syllable.

no bu-: $\quad$ a hyphen indicates an abrupt cut off of the prior word or sound.

(text): $\quad$ parentheses are used for transcriber's comments including description of

non-verbal behaviour

Text: $\quad$ bold indicates marked stress

TEXT: $\quad$ capitals indicate increased loudness

othanks ${ }^{\circ}$ : degree signs indicate decreased volume.

$\downarrow \uparrow: \quad$ arrows indicate shifts in high or low pitch

(:): $\quad$ smiley face indicates laughter

text: $\quad$ the stretches of transcript identified as formulaic are underlined

In some instances, the transcriptions are more affected by the phonological features of the language produced by the learners (e.g., escuse me for excuse me).

\section{References}

Bakhtin, Mikhail. 1986. The problem of speech genres. In Speech Genres and Other Late Essays. Translated by Vern W. McGee. Edited by Caryl Emerson and Michael Holquist. Austin: University of Texas Press, pp. 60-102.

Bandura, Albert. 1986. Social Foundations of Thought and Action: A Social Cognitive Theory. Englewood Cliffs: Prentice-Hall, Inc.

Bell, Nancy. 2005. Exploring L2 language play as an aid to SLL: A case study of humour in NS-NNS interaction. Applied Linguistics 26: 192-218. [CrossRef]

Bell, Nancy. 2012. Formulaic language, creativity, and language play in a second language. Annual Review of Applied Linguistics 32: 189-205. [CrossRef]

Bell, Nancy, and Stephen Skalicky. 2018. Humor and multi-word expressions in second language learning. In Understanding Formulaic Language: A Second Language Acquisition Perspective. Edited by Anna Siyanova-Chanturia and Ana Pellicer-Sanchez. New York: Routledge, pp. 115-31.

Broner, Maggie A., and Elaine E. Tarone. 2001. Is it fun? Language play in a fifth-grade Spanish immersion classroom. The Modern Language Journal 85: 363-79. [CrossRef]

Bushnell, Cade. 2009. "Lego my keego!": An analysis of language play in a beginning Japanese as a foreign language classroom. Applied Linguistics 30: 49-69. [CrossRef]

Cameron, Lynne. 2001. Teaching Languages to Young Learners. Cambridge: Cambridge University Press.

Carter, Ronald. 2004. Language and Creativity: The Art of Common Talk. London: Routledge.

Cekaite, Asta. 2018. Microgenesis of language creativity: Innovation, conformity and incongruence in children's language play. Language Sciences 65: 26-36. [CrossRef]

Cekaite, Asta, and Karin Aronsson. 2005. Language play, a collaborative resource in children's L2 learning. Applied Linguistics 26: 169-91. [CrossRef] 
Cho, Hyunhee, and Hoe Kyeung Kim. 2018. Promoting creativity through language play in EFL classrooms. TESOL Journal 9: e00416. [CrossRef]

Collins, Laura, and Carmen Muñoz. 2016. The Foreign Language Classroom: Current Perspectives and Future Considerations. The Modern Language Journal 100: 133-47. [CrossRef]

Cook, Guy. 2000. Language Play, Language Learning. Oxford: Oxford University Press.

Crystal, David. 1998. Language Play. Chicago: University of Chicago Press.

Davari, Hossein, and Ferdows Aghagolzadeh. 2015. To teach or not to teach? Still an open question for the Iranian education system. In English Language Teaching in the Islamic Republic of Iran: Innovations, Trends and Challenges. Edited by Chris Kennedy. London: British Council.

Enever, Janet. 2018. Policy and Politics in Global Primary English. Oxford: Oxford University Press.

Forman, Ross. 2011. Humorous language play in a Thai EFL classroom. Applied Linguistics 32: 541-65. [CrossRef]

Hann, David. 2017. Building rapport and a sense of communal identity through play in a second language classroom. In Multiple Perspectives on Language Play. Edited by Nancy Bell. Boston: Walter de Gruyter, pp. 219-44. [CrossRef]

Hasselgren, Angela. 2000. The assessment of the English ability of young learners in Norwegian schools: An innovative approach. Language testing 17: 261-77. [CrossRef]

Huth, Thorsten. 2017. Playing with turns, playing with action? A social-interactionist perspective. In Multiple Perspectives on Language Play. Edited by Nancy Bell. Boston: Walter de Gruyter, pp. 47-72. [CrossRef]

Jefferson, Gail. 2004. Glossary of transcript symbols with an introduction. In Conversation Analysis: Studies from the First Generation. Edited by Gene H. Lerner. Amsterdam: John Benjamins, pp. 13-31.

Lantolf, James. 1997. The function of language play in theacquisition of L2 Spanish. In Contemporary Perspectives on the Acquisition of Spanish. Edited by William R. Glass and Ana Teresa Perez-Leroux. Somerville: Cascadilla Press, pp. 3-24.

Laursen, Helle Pia, and Kirsten L. Kolstrup. 2018. Multilingual Children between Real and Imaginary Worlds: Language Play as Resignifying Practice. Applied Linguistics 39: 799-822. [CrossRef]

McKay, Penny. 2006. Assessing Young Language Learners. Cambridge: Cambridge University Press.

Mihaljevic Djigunovic, Jelena. 2015. Individual differences among young EFL learners: Age- or proficiency-related? A look from the affective learner factors perspective. In Early Learning and Teaching of English: New Dynamics of Primary English. Edited by Jelena Mihaljević Djigunović and Marta Medved Krajnović. Bristol: Multilingual Matters, pp. 10-36.

Myles, Florence. 2004. From data to theory: The over-representation of linguistic knowledge in SLA. Transactions of the Philological Society 102: 139-68. [CrossRef]

Myles, Florence, and Caroline Cordier. 2017. Formulaic sequence (FS) cannot be an umbrella term in SLA: Focusing on psycholinguistic FSs and their identification. Studies in Second Language Acquisition 39: 3-28. [CrossRef]

Myles, Florence, Janet Hooper, and Rosamond Mitchell. 1998. Rote or rule? Exploring the role of formulaic language in classroom foreign language learning. Language Learning 48: 323-63. [CrossRef]

Myles, Florence, Rosamond Mitchell, and Janet Hooper. 1999. Interrogative chunks in French L2: A basis for creative construction? Studies in Second Language Acquisition 21: 49-80. [CrossRef]

Nattinger, James, and Jeanette DeCarrico. 1992. Lexical Phrases and Language Learning. Oxford: Oxford University Press.

Nikolov, Marianne. 1999. 'Why do you learn English?' 'Because the teacher is short.' A study of Hungarian children's foreign language learning motivation. Language Teaching Research 3: 33-56. [CrossRef]

Pawley, Andrew. 2007. Developments in the study of formulaic language since 1970: A personal view. In Phraseology and Culture in English. Edited by Paul Skandera. Berlin: Mouton de Gruyter, pp. 3-45.

Pawley, Andrew, and Frances H. Syder. 1983. Two puzzles for linguistic theory native like selection and native-like fluency. In Language and communication. Edited by J. C. Richards and R. W. Schmidt. London: Longman, pp. 191-230.

Peters, Ann. 1983. The Units of Language Acquisition. Cambridge: Cambridge University Press.

Pinter, Annamaria. 2017. Teaching Young Language Learners. Oxford: Oxford University Press.

Pomerantz, Anne, and Nancy Bell. 2011. Humor as safe house in the foreign language classroom. The Modern Language Journal 95: 148-61. [CrossRef]

Reddington, Elizabeth, and Hansun Zhang Waring. 2015. Understanding the sequential resources for doing humor in the language classroom. HUMOR: International Journal of Humor Research 28: 1-23. [CrossRef]

Scott, Wendy A., and Yterberg Lisbeth. 1992. Teaching English to Children. London: Longman.

Tarone, Elaine. 2000. Getting serious about language play: Language play, interlanguage variation, and second language acquisition. In Social and Cognitive Factors in Second Language Acquisition: Selected Proceedings of the 1999 Second Language Research Forum. Edited by Bonnie Swierzbin, Frank Morris, Michael E. Anderson, Carol A. Klee and Elaine Tarone. Somerville: Cascadilla Press, pp. 31-54. Tomasello, Michael. 2003. Constructing a Language: A Usage-Based Theory of Language Acquisition. Cambridge: Harvard University Press. Toohey, Kelleen. 2000. Learning English at School: Identity, Social Relations and Classroom Practice. Clevedon: Multilingual Matters. Vygotsky, Lev. 1978. Mind in Society. Cambridge, MA: Harvard University Press.

Waring, Hansun Zhang. 2013. Doing being playful in the second language classroom. Applied Linguistics 24: 191-210. [CrossRef]

Wood, David. 2015. Fundamentals of Formulaic Language: An Introduction. London and New York: Bloomsbury.

Wray, Alison. 2002. Formulaic Language and the Lexicon. Cambridge: Cambridge University Press. 
Wray, Alison. 2014. Why are we so sure we know what a word is? In The Oxford Handbook of the Word. Edited by John Taylor. Oxford: Oxford University Press.

Wray, Alison, and George Grace. 2007. The consequences of talking to strangers: Evolutionary corollaries of socio-cultural influences on linguistic form. Lingua 117: 543-78. [CrossRef]

Wray, Alison, and Kazuhiko Namba. 2003. Use of Formulaic Language by a Japanese-English Bilingual Child: A Practical Approach to Data Analysis. Japan Journal of Multilingualism and Multiculturalism 9: 24-51. 